\title{
Case Study on Communication to Select Great Service Providers
}

\section{Do-Hee Kwon}

JEI University, Incheon, Korea

Objectives: Most foreign airlines conduct an interview process to find out if candidates have the required qualities for the job including the skills, knowledge, behavior and interpersonal skills based on the competence-oriented interview. The interview may predict how this candidate will contribute to the company through their past experience by asking in-depth questions. The purpose of the study is to communicate the importance of selecting great service providers who want to apply to international airlines.

Methods: This report is a brief case study that first examines web content on the airline interview process as well as related in-depth interviews with candidates who had interviews for airline jobs.

Results: When most airlines select their cabin crew, they focus on certain candidate characteristics, especially those qualities that can be improved through education programs and training in a short amount of time. Therefore, when candidates prepare for their interview, they should show that the qualities for the job are found in their personality, behavior patterns or habits and more importantly their communication skills. This leads to increased job satisfaction after hiring, especially in foreign airlines.

Conclusions: Cabin crews are the frontline service providers who not only directly deal with passengers from all around the world, but work with their colleagues as a team. Keep this required quality in mind: the ability to communicate fluently is the key factor for candidates who want to apply for international airlines. This study shows that applicants preparing for an airline interview are given the right direction to prepare for the interview.

Key Words: Cabin Crew, English Interview, International Airlines, Communication, Competence-Based Interview

\section{Introduction}

Being a member of an airline cabin crew is associated with a high salary, flexible work schedule, stylish uniforms, opportunities to meet people from diverse cultures, and opportunities to visit many countries. As a result, flight attendant is one of the most popular job choices among Korean young females (Kim,

Received: Sep 7, 2018 Revised: Oct 15, 2018 Accepted: Oct 30, 2018 Corresponding author: Do-Hee Kwon

JEI University, 178, Jaeneung-ro, Dong-gu, Incheon 22573, Korea

Tel: +82-32-890-7452, E-mail: feelfunfree@gmail.com

This is an Open Access article distributed under the terms of the Creative Commons Attribution Non-Commercial License (http://creativecommons.org/licenses/ by-nc/4.0/) which permits unrestricted non-commercial use, distribution, and reproduction in any medium, provided the original work is properly cited.

Copyright $\odot 2019$ Korean Association for Business Communication.
2017). This leads them to attend university or private institutes to prepare them for this job. Some people choose to major in Airline Service and study flight attendant training curriculum for 4 years in university or 2 years of college. In 2006, 23 Korean universities were reported to offer Airline Service as one of their majors. This number rose to 36 universities in 2008 along with 33 2-year college programs. 12 more universities were added in 2011, and the total number of schools offering this major was around 80 in 2016 (Lee, 2014). This shows that many Korean women want to be a flight attendant (Park, 2005). However, most students do not feel confident enough in their English to pass the interview so some of them go to private institutes to improve their English or go abroad to fulfill their career. Even being proficient in English, however, there are still other quali- 
ties required for cabin crew such as communication skills. The purpose of this study is to examine the importance of communication for applicants who want to be selected by international airlines.

\section{Case Description}

The world is becoming more globalized and there are increasing numbers of foreigners coming to Korea as well as many Koreans traveling around the world. The airlines make a strong effort in their job interviews in order to select the right cabin crew for the benefit of the airline as well as customer satisfaction. Flight attendants are defined by Aviation Act of the Korea as cabin crew members who perform safety tasks such as escape and progress in an emergency, and have the knowledge, physical health and ability to board an aircraft.

Flight attendant is an important human resource for the airline and spends the most time with passengers so the attitude of flight attendant serving passengers at Moment of Truth is a critical factor in customer satisfaction, human resource management for flight attendant in terms of airline competitiveness and image enhancement is very important (Kim, 2005). The most important first step in maintaining and managing these important human resources is the recruitment of flight attendants, and because the image and corporate culture pursued by each company are different from one another, the selection of suitable personnel for each airline should be made (Cho, 2013).

The process of recruiting and training good flight attendants is an important strategic tool for passenger satisfaction and for generating profits for the company. The hiring of Korean flight attendants from foreign airlines is also part of this strategy. The number of people with Korean nationality employed in Korea or other countries as a flight attendant in foreign national airlines are in total 2,372 (Lee, 2014).

Many airlines want to hire cabin crew with Korean nationality and more people than ever are applying the international airline companies that offer a more flexible work environment and schedules (Lee, 2014; Kim, 2017). In order to become an international flight attendant, they have to pass the English interview for English proficiency, which is required for all cabin crew with international airlines like Emirates airline. Unlike domestic airlines, English ability is specified as a mandatory condition according to the criteria for hiring foreign airlines.

Emirates is the airline that employs more Korean flight attendants among Middle Eastern countries than other European and Asian countries (Lee, 2014). The reason to focus on the Emirates airline English interview for this study was that the number of people with Korean nationality employed is growing.
Emirates airline employs crew of over 130 different nationalities, and is a representative company with many opportunities to work with flight attendants from various countries, and has a corporate culture that respects and understands each other's culture, and is an important element of respect and understanding of the diverse culture of crew recruitment as there is a Western culture in which everyone can deal with each other in an equal position (Cho, 2013). Emirates airline began with just two aircraft in 1985 and now has more than 265 aircraft, is continuing to expand its new line by ordering 40 Boeing 787 Dreamliners worth 151 billion at the Dubai Air Show in 2017 (Emirates Group Careers, 2019). Due to this growth, the company has hired flight attendants from all over the world, and it has listed the right people on its website. For example, The Emirates airline shows that candidate is culturally aware and reflect who are professional, empathetic, progressive, visionary and cosmopoli$\tan$. These are the characteristics we look for when you meet us at an assessment day.

For competence-oriented questions during Final interviews, the keywords for preparing for the interview are S.T.A.R.: $\mathrm{S}$ for Situation, T for Task, A for Action and R for Result. The questions like what kind of situations, what was the task, how they acted, and what was the results are based on their past experience (Rogers, 2006).

For the final interview, the interviewer asks questions to build small talk for helping the candidate to feel comfortable and to not get nervous and relax candidates. The second stage includes open-ended questions like "What is the most satisfying work experience you've had?" This is a starting point to find out what kind of competence the candidate has. And then the next step asks core competency questions like S.T.A.R.

In this stage, the Interviewer finds out the candidates' information and competence and asks questions based on the candidates' resume and self-introduction (Rogers, 2006). For example, when candidate says she can deal with customer's complaints, the interviewer might ask when she has handled a customer's complaint, what she did or how she felt, how the customer may have felt and what she learned from that experience. When a question that is asked is based around the candidates' past experience that helps imply past behaviors indicate future behaviors. Therefore, if candidates want to show how much they want to be selected during the interview, then rather than stating the future about how hard you will work for; instead answer how hard you have worked in the past. So choose an experience that demonstrates a positive experience and then briefly what happened and then describe how you dealt with the situation, what you did and explain the outcome, and what you learned from the experience (Rogers, 2006). When candidate describe 
what happened and how she did, the service procedure might be similar but what you learned from the experience is different among candidates. This is a great way to communicate with the interviewer about who you really are, what you value and show the ability to discover meaning through experience.

The next stage is an affirmation to confirm if there are any misunderstandings or anything unsure about the candidate's answers. Finally, the closing stage is to close the interview and for the interviewer to know if any curious questions from the candidate.

\section{Discussion}

Not only are foreign airlines hiring Korean flight attendants by using the competence-oriented interview, but Korean Air decided to abolish the height restriction when hiring cabin crew and strengthen the selection of interviews to verify their performance starting in 2015. Also, Asiana Airlines deleted a photo box on its job application form from the selection of international flight attendants since 2015 . There are other changes in the hiring process as well as in the job interview questions.

Rather than focus on image, on the 2018 application form from Asiana Airline, it asks to write down the experience and reasons you want to praise yourself. On the 2018 Korean Air's application form the first question was to describe what the most important value in the applicant's life is and what specific work has been done by you. The second question was to describe one quality you think is the most important as a team player and how the candidate has shown it. In the future, these job-oriented employment trends will be more pronounced.

As a useful example, the application form in the interview process shows that the applicant should think about ways to extract meaning from their past experience and how to express them. It is important to look at how she passed the question about describing what is the most important value in the applicant's life and what specific work has been done. She answered that "the most important value in her life is a challenge. It's especially about overcoming the fear of new things". She answered with results first and then explained what happened and also how she felt about it. "I wanted to work for the Shilla Hotel to get work experience, but it was my first interview with a company, so I was nervous and afraid that I wouldn't do well. But I was able to do it with the determination that this was the beginning of my work experience. As I gained experience in service at the hotel, I was able to find my aptitude and enjoyed it". The last sentence shows how she dealt with it and what kind of impact it had on her and what she learned from that experience. Another example of how to answer what it means to you when it comes to your previous experience: "There was a fear of foreign passengers during the practice session at Air Korea but I thought fear was my desire to do well, so I memorized all the conversational sentences that I might need at the airport". This example shows what she had done to overcome the obstacle and lessons from the experience.

\section{Conclusion}

The interview may predict how this candidate will contribute to the company through their past experience through in-depth questioning. Their past behavior is indicative of future behavior. As Spencer and Spencer (1993) say, underlying characteristics such as motives, traits, and self-concept that can predict behavior lead to job performance. It is much more effective in many ways, including in time and cost, as it is difficult to develop or change the internal characteristics of talent such as motivation, traits, and self-concept. It is also not easy to develop the familiarity, customer orientation, and job positivity that are identified as a significant capability for flight attendants, and it is necessary to develop a recruitment system based on the ability to select people with some of those qualities first (Kim, 2005). In addition, communication between cabin crew and passengers in the designated space of the cabin is not only about a particular subject but rather the in-flight service procedure in which the crew shows basic expressions to serve passengers, answers to expected passenger demands, and to help them develop conversational skills. Therefore, communication with passengers is a critical part of the in-flight service and for the passenger comfort and safety, rather than just for the company image. As a service provider, how to show one's communication skills based on past experience is important throughout the interview process. It is said that anyone can do well when asked about one's future but hard to lie about one's past. Through past experience, we can predict a person's future behavior, and what can be predicted can be managed.

\section{References}

Cho, D. H. (2013). Research on criteria and evaluation factors for hiring of Korean flight attendant in foreign airline (Master's thesis). Sookmyung University, Seoul, Korea.

Emirates Group Careers (2019). Experience our world as part of your career. Retrieved from https://www.emiratesgroupcareers. com/cabin-crew/

Kim, J. Y. (2017). My dream! Flight attendant!: Prepare flight attendant interview (Master's thesis). Ewha University, Seoul, Korea.

Kim, W. H. (2005). Key competency modeling of airline's cabin crew: 
Focus on a airline (Master's thesis). Korea University, Seoul, Korea.

Lee, E. B. (2014). Case study of strengthening the interview training course for the foreign airlines cabin crew job (Master's thesis). Kwangwoon University, Seoul, Korea.

Park, S. Y. (2005). Needs analysis for English for flight attendants
(Master's thesis). Yonsei University, Seoul, Korea.

Rogers, C. (2006). The complete cabin crew interview manual. London, UK: CE Publishing.

Spencer, L. M., \& Spencer, S. M. (1993). Competence at work: Models for superior performance. New York, NY: John Wiley \& Sons. 